Published in N.J. Enfield \& T. Stivers (Eds.), 2006 Person reference in interaction: linguistic, cultural, and social perspectives. Cambridge: Cambridge University Press.

\title{
8 Principles of person reference in Tzeltal conversation
}

\section{Penelope Brown}

\subsection{Introduction}

How does one refer to persons in conversation? How does one pick out an individual from the myriad people in one's social world, so that the interlocutor(s) can home in on a specific individual with known properties - a face, a name, a social identity, a personality - immediately called up? This is a problem that is both frequent and universal, since talking about individual people - what they did, where they went, what they are like, what should be done with them or about them - preoccupies a large proportion of conversations around the world.

Achieving reference of any kind is a matter of achieving mental coordination, and person reference is perhaps especially tricky because participants have to coordinate on a definite, unique individual, not just a class of individuals. Foundational work in conversation analysis (Sacks and Schegloff 1979, reprinted this volume; Schegloff 1996a; see Introduction, this volume) has claimed that how reference to persons is formulated is governed by two basic preferences:

(1) RECOGNITIONALS are preferred: that is, when the recipient knows the individual, use a referring expression that allows him/her to recognize the intended individual - for example, a name, or a recognitional descriptor, a description 'designed for the recipient and chosen to indicate how the recipient knows the referent'. There also appears to be a preference for names over descriptive expressions in English-speaker talk.

(2) MINIMAL REFERRING EXPRESSIONS are preferred: that is, using just one referring expression. This means one discrete reference form, however lengthy it has to be to identify the referent to the recipient in the context.

If there is a conflict between these two preferences, successively relax (2) in favour of (1).

If the system wanted only to assure recognition, speakers could 'overtell', being more explicit than necessary, but in conversation speakers prefer not to 
overtell (Levinson 1987; see also Schegloff, this volume on recipient design). So an additional admonition might be this:

Don't be overexplicit or the recipient may make additional inferences (e.g., that you think s/he doesn't know the person).

These principles, phrased as speaker admonitions, appear to account reliably for how initial reference to persons - and nothing else (Schegloff's 'referring simpliciter', Schegloff 1996a, this volume) - is achieved in English. Exceptions exist, but they raise the possibility of additional information being conveyed by deviation from the unmarked usage (see Stivers, this volume).

But does this analysis hold for languages and speakers in cultures around the world? Referring to persons, unlike referring to inanimate objects and animals, is a socially delicate operation, since persons are circumscribed by social identities, hierarchical status, and taboos in ways that are highly variable across cultures. Looking at person reference in a small-scale, face-to-face society where everyone knows everyone else or can trace them through kinship relations, and knows many of them by multiple labels (predominantly kinship terms and names, but also by nicknames, titles, and role descriptors), might shed light on this question. This chapter examines initial references to persons in Tzeltal, a Mayan language spoken in a speech community with a social system quite different from the American and European ones where the majority of conversation analytic work has been done.

The society in question is the small rural community of Tenejapa, in the state of Chiapas in southeastern Mexico. In their language, Tzeltal, locally initial forms for third-person reference include the usual repertoire: kin terms, names, honorifics and titles, and descriptive labels of varying degrees of specificity. If speaker, recipient, or other people they know are related to the referent through 'kinship' of various kinds, a kin term (or other relational term like 'namesake') is, as we shall see, the unmarked ('default') option. Names and geographical location (of the referent's home base) are also frequently used, as are role labels (e.g., 'the teacher', 'the worker'), status markers ('the ex-president', 'the deceased') and other descriptive terms.

Inspection of initial references to persons in twenty-five Tzeltal videotaped conversations reveals that, in comparison with person-reference forms in English, two things are remarkable about Tzeltal usage. Initial reference forms are often fairly lengthy, combined into a series in a single referring expression that pins down the referent more exactly (e.g., 'my cousin Juan over at the school' or 'oldman Chikin where your cousin Alonzo's house is now').

More surprisingly, sometimes (in about 10 per cent of person references in the data examined) initial references combine more than one referring expression (e.g., 'the teacher in Juxalja' I Jose' or 'oldman our-excl. mother'sbrother I Manel Tujk' awil'). This raises the question of whether, contrary to the 
Sacks and Schegloff principles, there is actually no preference for minimization in Tzeltal person reference.

This chapter addresses the sequential properties of such combinations in Tzeltal talk, and assesses the extent to which they are a consequence of a lack of prompt recognition signals on the part of the addressee, or whether there are motivations beyond simply reference for their initial formulation in more than one referring expression. Is there a construction that looks less than fully minimal routinely employed in initial person reference, or are there interactional reasons to do with identification of referent (uptake, common ground, etc.) for each of these expanded forms? I will argue that there is a culturally elaborated preference for 'association', locating individuals referred to in relation to the speaker or addressee, and a tendency to go beyond 'simply referring' to specify the referent's position in the social and geographical network of Tenejapan society. To preview my conclusions: I show (1) that 'kinship' rather than 'name' is the default system for recognitional person reference in this society, (2) that the Sacks and Schegloff principles of recognition and minimization are indeed supported by the Tzeltal data, and (3) that a major way in which the preference for minimization gets relaxed is to associate the referent to the speaker, addressee, or both. I therefore propose a slight modification to the CA preference rules for initial person reference.

\subsubsection{Ethnographic background}

Tenejapans are Mayan farmers, growing corn and beans in a largely subsistence lifestyle although some coffee and other crops are grown for sale. Their community is in a remote ruggedly mountainous area of highland Chiapas, and until recently there were no all-weather roads into it, so many people are still relatively isolated from the surrounding Mexican national culture and are effectively monolingual in Tzeltal. Tenejapa is bordered on the east by other Tzeltalspeaking communities ( $\mathrm{K}^{\prime}$ ankujk, Oxchuk), but from the northwest to the southeast it is bordered by Mayan communities that speak the closely related language Tzotzil (Chenalho', Mitontik, Chamula, Huistan). Increasingly, intermarriage from across these borders means that some Tzeltal households have Tzotzil-speaking wives in them, with corresponding bilingualism in the home. Greatly increased schooling and mobility in the past 20 years has made people under the age of about 35 partially bilingual in Spanish. But Tzeltal remains the primary language of the community and is universally spoken in the home.

Like inhabitants of each of the neighbouring Mayan municipios, Tenejapans have their own distinct identity with their own local political system, characteristic dress, dialect variations, and economic and cultural practices. They recognize a basic split in kinds of people: Mayans ('us', indigenas, including the other indigenous people around them) versus 
Ladinos ('them', kaxlanetik) who speak Spanish and belong to the politically and culturally dominant group in Mexico. They have increasingly become aware of a third kind of people, gringos or turistas, that is, foreigners, especially since the town of San Cristóbal de las Casas, about 25 miles away, has become a tourist mecca. At a more fine-grained level, they distinguish Tenejapans - jlumaltik 'our-inclusive countrymen' - from the people of other municipios, the K' ankujketik, Oxchuketik, Tzotzleb and so on. Within Tenejapan society, social distinctions are based mainly on sex, age, and seniority due to those who hold, or have held, ritual or political office in the community.

There are about 37,000 Tenejapans, living in scattered homesteads in named hamlets (parajes), surrounded by fields. They do not all know each other personally, but they are related to one another through a classificatory kin system as well as through godparent relations (compadrazgo) and can usually trace the relationship of any Tenejapan to someone they do know.

\subsubsection{Data sources and method}

I have been working in Tenejapa over a period spanning 35 years, collecting recordings of naturally occurring Tzeltal conversation as part of my research program. For this chapter, I have used only videotaped data (collected since 1980), so that visual aspects of person reference (e.g., gaze, pointing) can be brought into the analysis. I examined twenty-five conversations for the forms of initial third-person reference used, both two-party and multiparty conversations. They range from 3-minute interchanges to leisurely conversations of a couple of hours, including visiting conversations, relaxed chat between siblings at home, talk over tasks like making tortillas, functional visits to obtain things from a neighbour, and the like. The number of different participants in these conversations is more than forty, and the total number of third-person references examined is about 1200 .

Initial references to persons were coded for the following properties: formulation as recognitional or non-recognitional, form (kin term, name, honorific, title, description, etc.), complexity (minimal or non-minimal), accompanying pointing gestures and uptake.

\subsection{Resources for doing person reference in Tzeltal}

Here I set out the main linguistic and other communicative resources for referring to persons. Note that use of any of these forms will, if applicable, be accompanied by a socially more or less obligatory further specification: (1) by an age designator (mamal 'oldman', me'el 'oldwoman') indicating that the 
referent is over the age of about 50, or (2) by the word anima 'deceased' if the referent has died. They may also be (and often are) accompanied by (3) pointing to the referent's home base location, adding quite specific and accurate information allowing the referent to be identified (see also Levinson, this volume).

\subsubsection{Kin terms and other relationship terms ('your brother-in-law', 'your namesake' 'our-inclusive compadre')}

Kin terms are, I shall argue, the default reference form whenever there is a kin relation of the intended referent to either the speaker or to the addressee, or to someone else related to either of them. But what does it mean to have a kinship relation in this society? Tzeltal has a classificatory kinship system, with kin terms like 'brother' and 'sister' extended indefinitely outwards to kin collaterally and in ascending and descending generations. Patrilineal clans are indexed with surnames; patrilocality means that women generally marry into a hamlet, so that hamlets are associated with particular patrilines and therefore with particular named clans.

The kinship system is of the Omaha II type (Lounsbury 1969), with father's sister (-wix) structurally equivalent to elder sister, grandchildren equivalent to grandfather, and female's brother's son (-ijtz'in) equivalent to female's younger brother. Cross-cousins are distinguished from parallel cousins, the latter being equivalent to ego's siblings, while patrilateral crosscousins are equivalent to ego's children and matrilateral cross-cousins to ego's mother's brother and mother's sister. Terms denoting kin of the same generation or one younger generation are mostly distinguished by sex of propositus (the 'anchor' in Downing's, 1996, terms) and by sex of referent. All this means that these kin terms are informationally rich - indexing things like relative age, sex of propositus, sex of referent, and generation of referent - conveying more information about the referent than do personal (first) names in Tzeltal.

In all, twenty-six kin terms are used for consanguineal and affinal relations. (See Table 8.1.) These are pervasive as person-reference forms in my data. Two other relationship types also frequently appear in person reference: adults related through godparenthood (-kumpare, -kumare), and a special term for someone with the same first name (-jelol). There is also a special word for the youngest child in a family ( $k^{\prime} o x$ ). Only a few of these terms are unique identifiers (those for mother, father, husband, wife, and $k$ 'ox at any given point in time), with most referring to a potentially wide range of individuals (although when necessary a 'real' brother, etc. can be specified by the word batz'il 'real' modifying the kin term). 
Table 8.1 Tzeltal kin terms*†

Lineal

Parents: -me', -tat

Siblings: -wix (ElSi), -bankil (ElBr, male ego), -xi'lel (ElBr, female ego), -ijtz'in (YoBr)

Children: -al (female ego), -nich'an (male ego)

Grandchildren/grandfather: -mam

Grandmother: -me'chun (FaMo and MoMo)

Collateral

Father's brother: -tajun

Father's sister: -wix [same as ElSi]

Mother's brother (and MoBrSo): -ichan

Mother's sister (and MoBrDa): -me'jun

Children of brother: -ijtz'in (female ego): -nich'jun (male ego)

Children of sister (male ego) -ichan [same as MoBr]

Sons of sister (female ego): -aljun

Daughters of sister (female ego): -antzial

Affines

Husband: -mamalal

Wife: -inam

Fa-in-law/son-in-law: -nial

Mo-in-law/daughter-in-law: -alib

Brother-in-law: (male ego) - bal , (female ego) - mu'

Sister-in-law: (female ego) -jawan, (male ego) -ти'

HuBrWi: -it'ix

MoBrWi: - chich

* Abbreviations for core kin relationships are: $\mathrm{Mo}=$ mother, $\mathrm{Fa}=$ father, $\mathrm{ElSi} / \mathrm{ElBr}=$ elder sister, elder brother, $\mathrm{YoSi} / \mathrm{YoBr}=$ younger sister, younger brother, $\mathrm{Da}=$ daughter, $\mathrm{So}=\mathrm{son}, \mathrm{Hu}=$ husband, $\mathrm{Wi}=$ wife. These are combinatorial; thus $\mathrm{MoBrSo}=$ mother's brother's son (i.e., a crosscousin)

$\dagger$ Based on Brown (1979:142-148)

This multiple ambiguity is expanded dramatically because these kinship terms are extended to everyone in the same clan (of which eight appear in my conversational data), even if the exact relationship cannot be traced. In other words, everyone with the same Spanish surname is treated as kin with these same kin terms. So, for example, if I'm Xun Gusman Ch'ijk, all people 
with the surname Gusman are my 'brothers'/'sisters'/'uncles'/ 'aunts' and so on depending on generation, sex and relative age. Similarly, my mother being a Lopez, all Lopezes are treated like my maternal-line kin, and if my in-laws are Mendes (e.g., my brother married a Mendes girl) then all Mendeses are my 'in-laws', and so on. As a result, virtually everyone in Tenejapa is related to everyone else, either by blood, clan membership, marriage or godparenthood. Therefore most person references are (potentially) recognitional - they can be elaborated on until the kinship links are clear. But the corollary is that there is potentially huge ambiguity of kin term alone as a reference form.

When used in person reference, Tzeltal kinship terms are obligatorily possessed, so the 'propositus' (the person through whom the relationship is reckoned) is always cross-referenced - the link to speaker (e.g., 'my mother'), to addressee (e.g., 'your elder sister'), or to third party (e.g., 'Xun's grandfather'). To talk about a kin relation type one adds a nominal suffix: for example, wixil 'elder-sisters in general'. There is a certain amount of flexibility in how the relationship is reckoned: it can be reckoned - 'triangulated' through father's side versus mother's side, or through the addressee's relationship versus the speaker's relationship to the referent ('my-mother' versus 'your aunt'). In these data, it appears that reckoning through the speaker or addressee is preferred, where possible, to reckoning via the referent's relation to a third party. (See Haviland, this volume, for the same 'altercentric' pattern among the closely related Tzotzil Mayans of Zinacantán.)

Kinship relations are indexed by the Tzeltal naming system, to which we now turn.

\subsubsection{Names}

Two distinct trinomial naming systems are operative in Tenejapa. These are used in different contexts, and provide different information about the kin connections of the referent. Every Tenejapan has a Tzeltal name consisting of a first name, a second Spanish-derived clan surname, and a third Tzeltal patriline subclan name. For example, a person with the name Xun Gusman Ch'ijk has as her first name Xun (drawn from a set of about twelve girls' names); the Gusman refers to a larger exogamous grouping (associated with a specific set of Tzeltal patriline names), and Ch'ijk is the patriline surname. Both Gusman and Ch'ijk names come from her father, but the larger grouping Gusman defines the boundaries of exogamy; you should not marry someone with the same clan surname. Women do not change their names on marriage.

Everyone also has a corresponding Spanish set of names (for school, official documents, etc.). For example, Juana Gusman Lopez could be the Spanish 
trinomial name for Xun mentioned above, with Gusman from the father and Lopez from the mother in the Spanish fashion. Thus this set of names does not include information about the patriline (Ch'ijk), but adds the information about the mother's clan association (Lopez).

Both systems are in use in conversation, although the Tzeltal names predominate, especially for anyone over the age of about $30 .{ }^{1}$ Reference via surname can use the Spanish (clan) or Tzeltal (lineage) name (e.g., Gusman or Ch'ijk), or both. Using the Spanish name may convey something about public role - either the setting is public (school, public meetings, voting) or the person's relevant-in-context role is public (e.g., teacher, committee chairman). Similarly, for first name reference you can use the Spanish or the Tzeltal first name (e.g., Juana or Xun). Some younger individuals use their Spanish first name as default, but most people have the Tzeltal name as the default.

There are only a dozen Tzeltal first names for men and the same number for women that appear in my data, and a handful of these (Alux, Antun, Petul, Xun, Xmal) are favourite names, so that every Tzeltal household with several children is likely to have children with the same name as adults in the household and also with the same name as some of the people in every other household. As a result, there is a huge ambiguity of first name alone as a reference form. Names for adults are dispreferred, rarely used among persons sharing a household, and names for one's household members are rarely used for non-household members.

There are more Tzeltal surnames than first names, but, due to patrilocal residence, in a given hamlet most men share one of only ten or so surnames as well. Married-in women drawn from the whole pool of Tenejapa have a wider range of surnames. In conversation, referring to people by their family name only - for example, 'woman Chikin', 'girl Tukut', 'boy Osil' - implies that the speaker (or addressee) does not know them well.

A third kind of name - nicknames - is another solution to person reference. What these are for any individual is in-group knowledge; they are usually mocking (referring to personal appearance or history, as in the long descriptive nickname in (1)), and are not normally used when the referent is co-present.

\section{(1)}

bankilal tz'et wale' lo'bal

'elder-brother cuts_down_at_base sugarcane and bananas' 1 This contrasts with usage in the neighbouring municipio of Zinacantán, where the Spanish
system of naming is hardly used (Haviland, pc). 
Because they are generally used only within the in-group, nicknames are very successful as initial person-reference forms, unambiguously picking out the intended referent with the associated mocking stance.

\subsubsection{Honorifics and role labels}

Two generic honorifics are frequently used. These are jtatik, literally 'father' plus a plural/honorific suffix -tik (a form that I gloss as 'sir'), and jme'tik 'mother' + honorific -tik (which I gloss as 'madam'). ${ }^{2}$ Using these terms in reference or address or adding them to a name conveys respect to the referent, so is an indication of relative status/age of speaker and referent. For parents-inlaw there are default interpretations of these honorific expressions: jtatik ku'un 'my sir', is the normal way to refer to one's father-in-law, and jme'tik ku'un 'my madam' for mother-in-law.

Other socially expected honorifics are titles for holders of a political or religious office, still used after the referent has left office, when (s)he's referred to as 'the former $\mathrm{X}$ ':

(2)

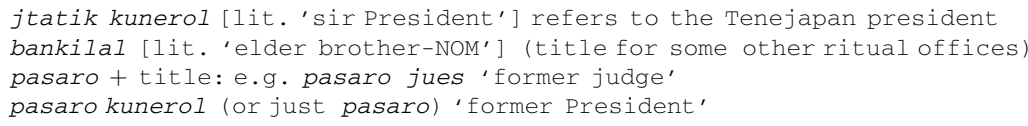

A role label (indexing the most relevant or most recent role) is the default reference form for school teachers (maestro, maestra), and for holders of high religious (Kawilto) or political offices (President, Judge, Scribe, etc.). People in a relationship of compadrazgo (godparenthood) use 'compadre', 'comadre', as default reference forms, indexing the special respect due in this relationship (see also Hanks, Haviland, this volume).

\subsubsection{Minimal descriptions ('that one' 'the girls', 'the boss')}

Minimal descriptors are frequently used as initial person-reference forms. Often they are non-recognitional, but Example (3) shows two recognitional 2 The $j$ - prefix is a classifier for humans; it also indicates + human on nominalized expressions
for kinds of people (e.g., j'a'teletik 'workers', $j$ 'aneletik 'fleeing people'). 
ones (initial reference forms are in boldface in the gloss line, in boldface and underlined in the text line):

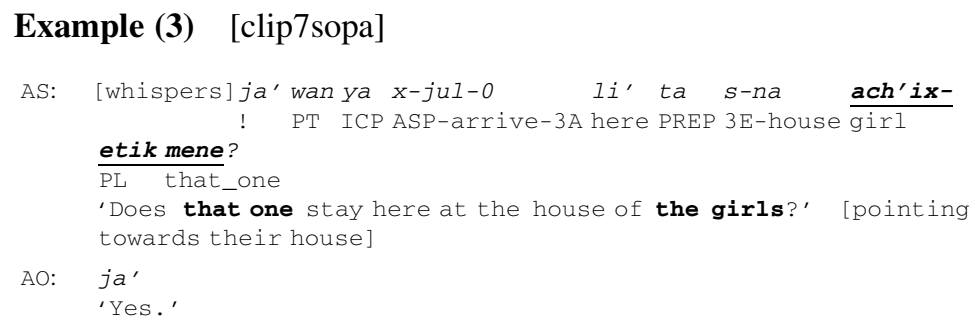

AS's whispered question to AO is about a co-present person (me), and 'the girls' referred to are unmarried grown women (over age 40), so in this situation, circumspection is in order (see Levinson, this volume). Another situation where minimal descriptors are often used is in referring to one's own children, using, for example, 'my-child', 'the boy', 'our-exclusive youngest boy' or 'this little elder brother' instead of a name.

\subsubsection{Pronominal cross-referencing on the verb ('he/she', 'they')}

Tzeltal freely allows ellipsis of nominal arguments, with person obligatorily cross-referenced on the verb. While these are not forms dedicated to initial person reference, one of these person cross-referencing markers is sometimes the only morphosyntactic evidence for reference to a newly introduced person. The third-person singular cross-reference form in Tzeltal is zero, with third person overtly marked only in the plural. Tzeltal is a verb-initial language, so that technically, ALL initial person reference (except in special cases where the nominal referent is in focus and moved to the left of the verb) is via the cross-referencing on the verb, before the noun phrases that (optionally) follow the verb and specify the person referent and other participants. Cases where the verb is immediately followed by the explicit noun phrase(s) I have not treated as cross-referencing only. An example of initial person reference with crossreferencing only can be seen in Example (4) (in the turn marked $->$ ):

Example (4) [mampak2, talking about a man who went down to where AN's cornfields are]

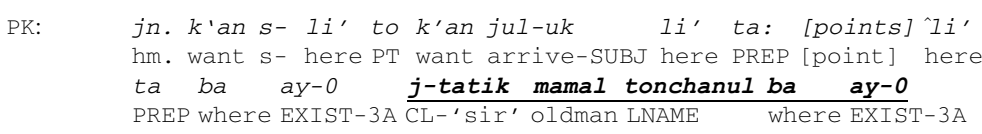




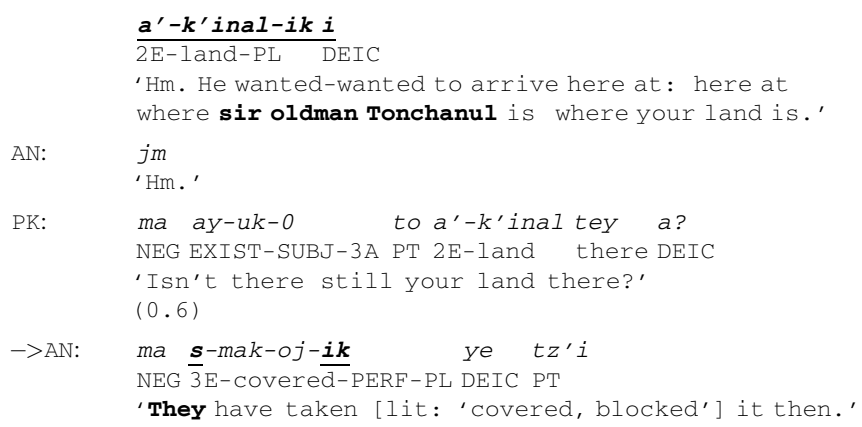

AN's reply to PK's question - Don't you still have your land there? - strategically does not mention who it is who has taken over his land, generating the next topic in the conversation. Formulation in this way lets the recipient know that a third-person referent (singular or plural) is being referred to, but beyond that indicates nothing about whether it is a person or who the person is. ${ }^{3}$

\subsubsection{Summary: default person-reference forms}

From the foregoing it can be seen that what is default initial person-reference usage in Tenejapa (as indeed, I expect, everywhere) depends on the social identity of the referent and on their relationship (if any) to speaker, to addressee, and to other coparticipants. To recap: Insofar as there is a general default, it is kin terms, since most people in Tenejapa are connected through kinship (including fictive kin, those 'related' by virtue of having the same Spanish surname). Prima facie evidence for this as the default is provided by simple frequency: Kin terms outnumber other kinds of initial reference forms in conversation (46 per cent, as opposed to 13 per cent names; see Table 8.3). Other defaults apply in particular circumstances, as we have seen: for example, the generic-honorific reference forms (jme'tik, jtatik) for older people in a household and for in-laws, relationship (komare/kompare) terms for co-godparents. Reference to children in one's own family, if well known to addressee, often uses a first name or nickname (preceded by ch'in 'small' if under age 8 or 10 , or if the referent has to be distinguished from an older sibling or cousin with the same name) or $k$ 'ox 'youngest'; outside the family context it is 'child of $X$ '. For people who are not kin to speaker or addressee, and are socially somewhat distant, the default is jme'tik/jtatik + name

3 Actually, the pronoun system supplies one more bit of information in first-person-plural references: there's a distinction between we-inclusive and we-exclusive, indexing whether or not the addressee is included in the reference. 
Table 8.2 Considerations entering into default person reference

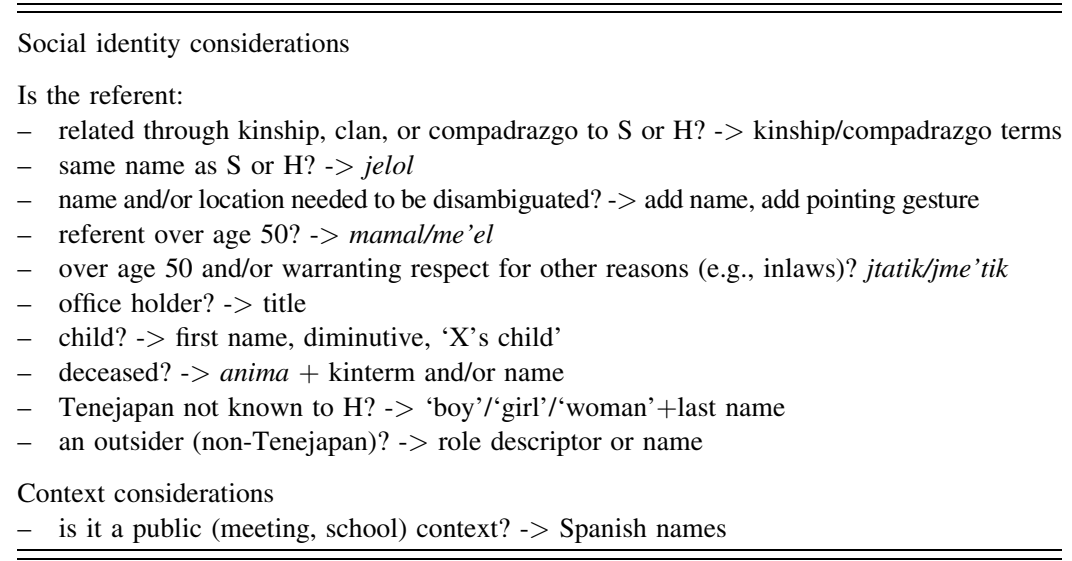

(respectful), or me'el 'oldwoman'/mamal 'oldman' + name (neutral or disrespectful), or a full name. Tenejapans who are not personally known to the addressee are referred to as 'girl'/'boy'/'woman' + surname (e.g., ach'ix Mentes 'girl Mendes', antz Ernandes 'woman Hernandez'). For nonTenejapans whom the addressee is not expected to know personally (strangers), person- reference is generally just with a title or descriptive term (e.g., senyora, maestra, superintendente, jkaxlan) or a role descriptor, plus or minus a name. Use of the classifier jtul 'one-human' indicates that the recipient is not expected to recognize the referent.

These minimal default forms are modified or overridden in particular circumstances. If the person referred to is dead, then the reference form is preceded with anima 'deceased'; this is done at first mention and then not carried on through subsequent mentions in the same local context, but if the referent is re-introduced at a later point, anima is again by default used. And all defaults for known persons are overridden by a form used if the speaker or recipient shares a first name with referent - then -jelol 'my-namesake' (or 'your-namesake') is the default form. This narrows down the range of possible referents to those who share my/your name. It is not obligatory, but expected for intimates and close kin and is a way of foregrounding the relationship. Respectfulness is expected for reference to old people, and to people who have (or have had) political or religious office, warranting honorifics, or title of office held, and sometimes a name as well (e.g., 'the former old-man scribe, this oldman Pak'el').

A summary of the kinds of considerations entering into default choices of initial reference form in Tzeltal is provided in Table 8.2. 
Departures from these default uses carry additional meanings. For example, to convey positive affect (affection) for close family members, you can precede the first name or 'girl'/'boy' descriptor with $k$-ala 'my little' (especially for one's own children or grandchildren), or use a diminutive suffix -il or $-u c h$ on the name (e.g., Xmaruch is the diminutive for Xmal). To convey negative affect you can use mocking nicknames or descriptors. Finally, particular taboos operate; for example, women avoid saying 'my-husband', using a more indirect reference form instead.

\subsection{Initial references to third persons in Tzeltal conversation}

\subsubsection{Overview}

To get a sense of the relative frequency of these different forms of person reference in Tzeltal, I counted initial person references in a one and a half hour conversation. There were two main participants (plus the cameraman), with one man visiting an older one living in a different hamlet. The two are related as 'fictive kin' because the old man's Spanish surname is Perez, the same name as the younger man's mother's (making the older a 'mother's brother' to the younger). But they hadn't seen one another for several years. Table 8.3 presents the numbers for different person-reference forms in their conversation.

The categories I counted are NAmE (e.g., 'Pedro Gomes', 'old man Chikin', 'the deceased Erismo', 'Juan Gusman here' + pointing gesture), KIN TERM alone (e.g., 'my deceased father', 'your MoBr', 'her husband') or specified further by name or location ('the ElSi of oldman Alonso Gusman here downhill', 'the grandparents of your MoBr Alonzo here', 'my 'sir' [i.e., Fa-inlaw] oldman Yeko Perez'), minimal Description [e.g., 'the woman', 'the carpenter', 'the 'boss', 'my boy', 'the priest', 'that one' + pointing gesture), EXTENDED DESCRIPTION (e.g., 'the maid of oldman Kirixpin', 'the Kawiltos at the back of the mountain', 'the one married to the Chikin woman'), and CROSS-REFERENCING ALONE (e.g., 'They have taken it then' in Example (4)).

As can be seen from Table 8.3, on frequency grounds kin terms are the default, occurring as all or part of almost half the total initial person references. The majority of person-reference forms (69 per cent) are either kin terms or minimal descriptions. Starting with a name is relatively rare, but names are often added as second information after a kin term ('my cousin Alonzo'). The names are as frequent as they are (13 per cent) partly because 26 out of the 116 kin term reference forms are expanded with the name of the propositus. Although 54 per cent of the person references in this sample conversation do not have a kin term, this is usually for clear reasons (e.g., no kin link [reference is to outsiders, or to mythical people], or referent is a young child). 
Table 8.3 Initial person references in one 1.5 hour dyadic conversation

\begin{tabular}{|c|c|c|c|c|c|}
\hline & $\begin{array}{l}\text { Alone or with } \\
\text { other linguistic } \\
\text { specification }\end{array}$ & $\begin{array}{l}\text { With a } \\
\text { pointing } \\
\text { gesture }\end{array}$ & $\begin{array}{l}\text { Elaborated } \\
\text { with other } \\
\text { linguistic } \\
\text { specification* }\end{array}$ & $\begin{array}{l}\text { Non-minimal, } \\
\text { with another } \\
\text { referring } \\
\text { expression* }\end{array}$ & Total \\
\hline Name & 20 & 14 & (5) & $(5)$ & $34(13 \%)$ \\
\hline Kin term & 76 & 40 & (29) & (16) & $116(46 \%)$ \\
\hline $\begin{array}{l}\text { Minimal } \\
\text { description }\end{array}$ & 51 & 8 & (1) & 0 & $59(23 \%)$ \\
\hline $\begin{array}{l}\text { Extended } \\
\text { description }\end{array}$ & 22 & 8 & & (3) & $30(12 \%)$ \\
\hline $\begin{array}{l}\text { Cross-referencing } \\
\text { alone }\end{array}$ & 13 & 2 & & 0 & $15(6 \%)$ \\
\hline Total & $182(72 \%)$ & $72(28 \%)$ & & 24 & 254 \\
\hline
\end{tabular}

* Note that these are subsets of the total represented in the first two columns.

Extra information beyond that in the reference form chosen is often provided by concurrent pointing. Pointing localizes the home territory of a referent accurately (height of pointing arm indexes distance, and the point's direction is very precisely calibrated). Pointing to the referent's home base is very frequent with kin term and with name (more than 50 per cent of cases), but much less so with descriptions and with zero (cross-referencing alone). Pointing alone without a verbal reference is rare.

As mentioned above, Tzeltal references to persons, when compared with what we find in English usage, are notable on several counts. Firstly, as just discussed, kin terms rather than names are unmarked. Secondly, even when minimal (one referring expression), initial references are often relatively longwinded (e.g., a complex noun phrase). This can be accounted for on at least two grounds: (1) ambiguity of kin term alone or name alone motivates kin term + name + location as the minimal information necessary to delimit the intended referent to this particular interlocutor, and (2) as we have seen, if relevant, certain information must be conveyed - if the referent is deceased, or over the age of 50, or a former officeholder, for example. Another noteworthy feature mentioned earlier is that, quite often, initial referring expressions are non-minimal, consisting of two or more noun phrases uttered under one intonational contour, as in (5):

\section{(5)}

\footnotetext{
'[deceased oldman] [my grandfather] [this oldman Petul Ch'ijk']'

' [my mother's brother] [Lorenzo] [the husband of my aunt X'anton]'

' [my grandchild] [the boy of yours]'
} 
How many of the reference forms in the data examined were 'non-minimal' in this way? Consulting Table 8.3, we find that, of 254 initial person references, 24 of them - almost 10 per cent - are non-minimal. Clearly, minimization as a principle holds in Tzeltal, applying to 90 per cent of the cases. But what accounts for the non-minimal ones?

Let us look at some of these initial person references in Tzeltal conversations. First I'll give some examples of referring expressions that are indeed minimal - one referring expression (one noun phrase) under one intonation contour. In the examples, boldface and underlining in the Tzeltal line indicates third-person references that are initial in the local context; underlining alone marks non-initial person reference in the context.

\subsubsection{Minimal person reference in Tzeltal}

Truly minimal reference forms occur in conversation within a context where reference is presumed to be unambiguous. This can be readily seen on first arrival of a visitor at someone's home, asking for the eldest man in the household with the term jtatik, as in:

\section{Example (6) [chanit]}

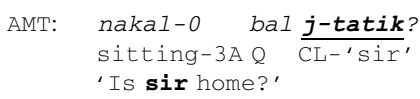

or, in contrast, for the young man of the household with a first name, as in:

\section{Example (7) [colonia1, v6A]}

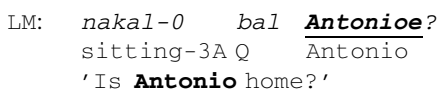

The physical context where talk takes place may alone be sufficient to make reference with a simple kin term unambiguous, as in:

Example (8) [trees1; five men trimming branches off of trees next to the house of the 'elder sisters' of MO, the 'aunts' of X]

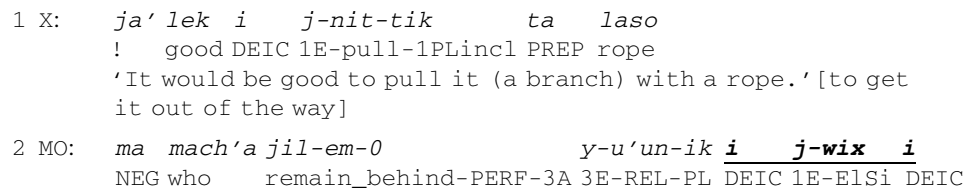




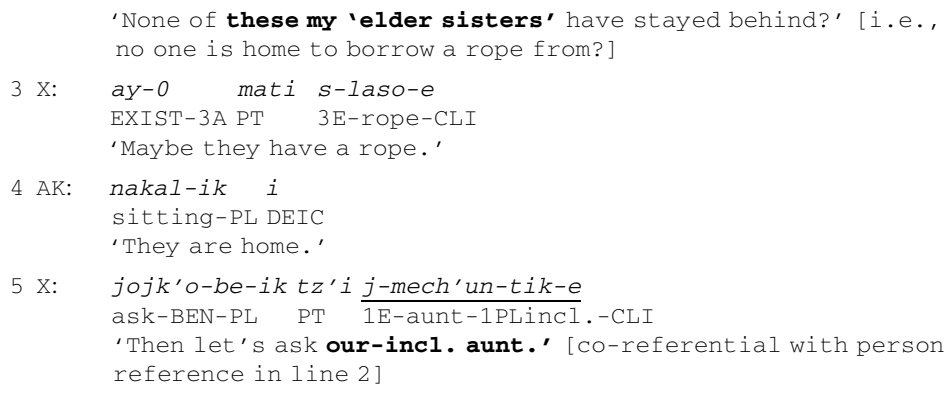

Apparently long-winded but indeed minimal initial person references, using one referring expression - one noun phrase under one intonation contour include the following:

Example (9) [sluskox2; AN is visiting SL who now lives in town; they are talking about when they first met one another, years ago]

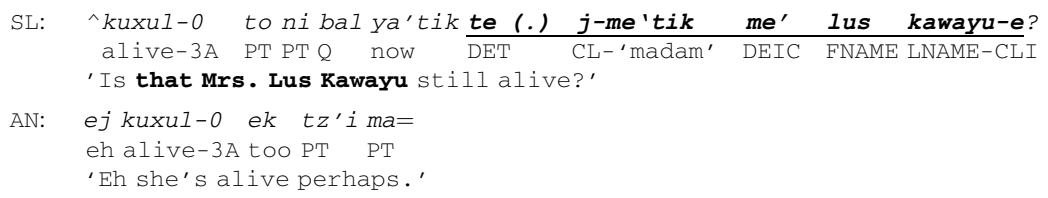

In this first reference to a woman whom AN took up with, as his second wife, at the time when he first met SL, the 'madam' indexes the referent's age, while the full name reflects the fact they have not spoken about this woman to each other for more than 20 years.

The addition of location information, and an index finger point, yields two sources of information, making the reference more explicit, as in Example (10):

Example (10) [mampak2; AN is visiting PK, they are now talking about a man going down to AN's corn fields]

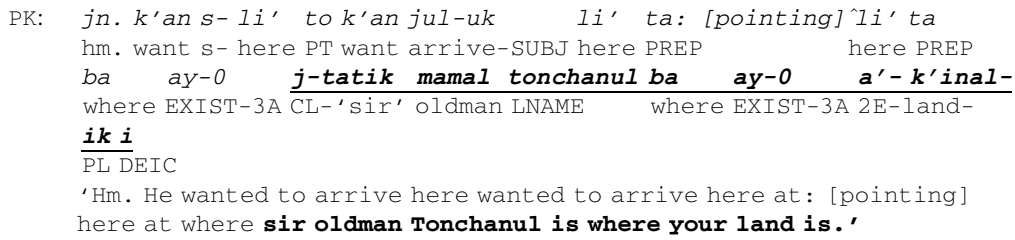

In contrast with the previous example, Example (11) is non-minimal. Here the additional information deemed necessary is descriptive rather than locational: 
Example (11) [matxil; AN and MXs talking about AN having moved away from the hamlet of Majosik'; MX is asking whether AN still has communal responsibilities to Majosik']

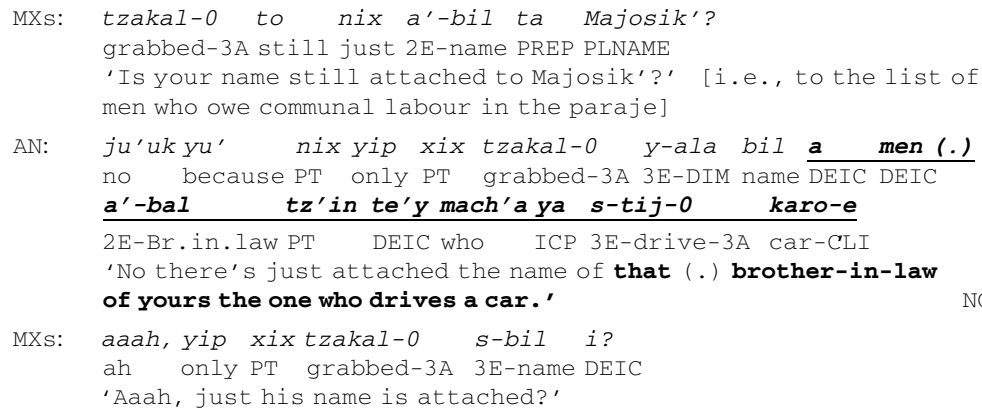

MXs: aaah, yip xixtzakal-0 s-bil i? ah only PT grabbed-3A 3E-name DEIC

'Aaah, just his name is attached?'

Here the reference is to AN's own son, but is phrased in terms of the referent's relationship to MXs ('your Br-in-law'); AN's descriptor 'the one who drives a car' serves to pick out which one of his five sons is intended.

Choice between alternate forms of reference for a given referent that are equally known to the addressee may be conditioned by what the topic is at that point. In Example (12), Spanish rather than Tzeltal names are used for the referents summoned to work, full Spanish names being the default usage for work summonses. (Note that one of these references is expanded into a nonminimal expression in line 7, phrasing the relationship through both speaker and recipient):

Example (12) [manosil\&AO, v16A: conversation between classificatory 'brothers' about a quarrel between MA's son and his wife, talking about the son failing to show up for a hearing about the quarrel]

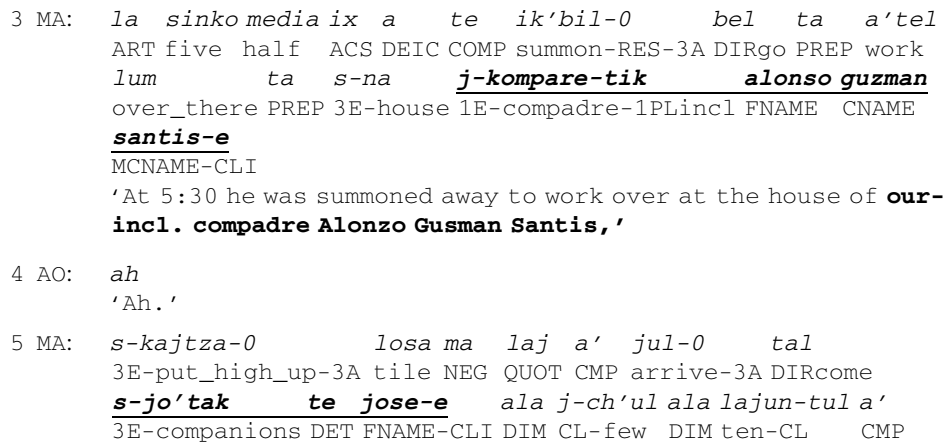




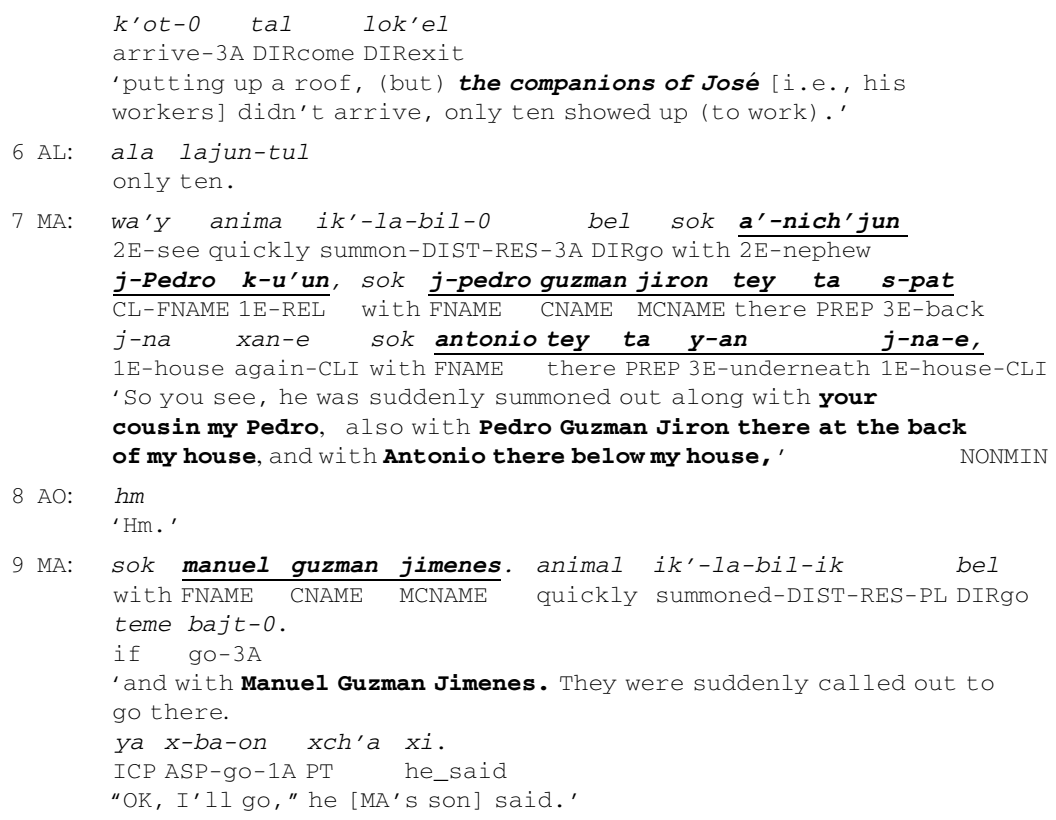

The reference forms here include first name alone (José), full Spanish trinomials, in one case expanded with 'our-inclusive compadre', in other cases with location information.

Another basis for choosing among alternative reference forms is the tendency, when a referent is related to both speaker and addressee, to 'take the perspective of the other' and use the form with the relationship reckoned through the addressee rather than through the speaker. We have already seen an instance of this in Example (11) (where 'your brother-in-law' refers to the speaker's own son). Another example occurs in (13):

Example (13) [sluskox2; AN is visiting SL in San Cristóbal, where she now lives, catching up on gossip and personal history]

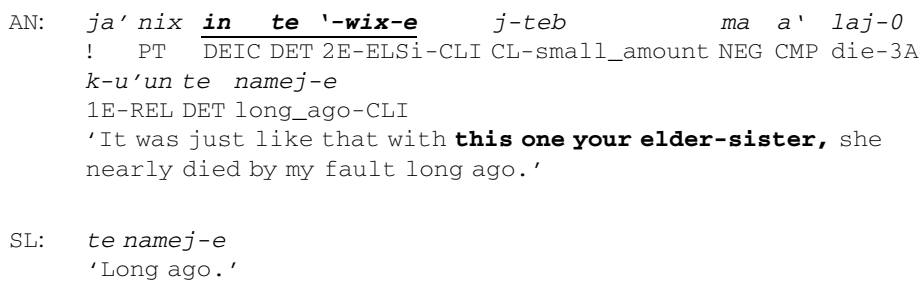


Here AN introduces the topic of his own wife's illnesses years ago by referring to her as 'this one your elder sister', a classificatory relationship calculated through AN's wife who shares the Spanish clan name Gomez with SL. This kinship reckoning, triangulated sometimes with great elaboration, is done on the fly, as when later in the same conversation SL refers to her own husband as a'nial 'your deceased father/son-in-law':

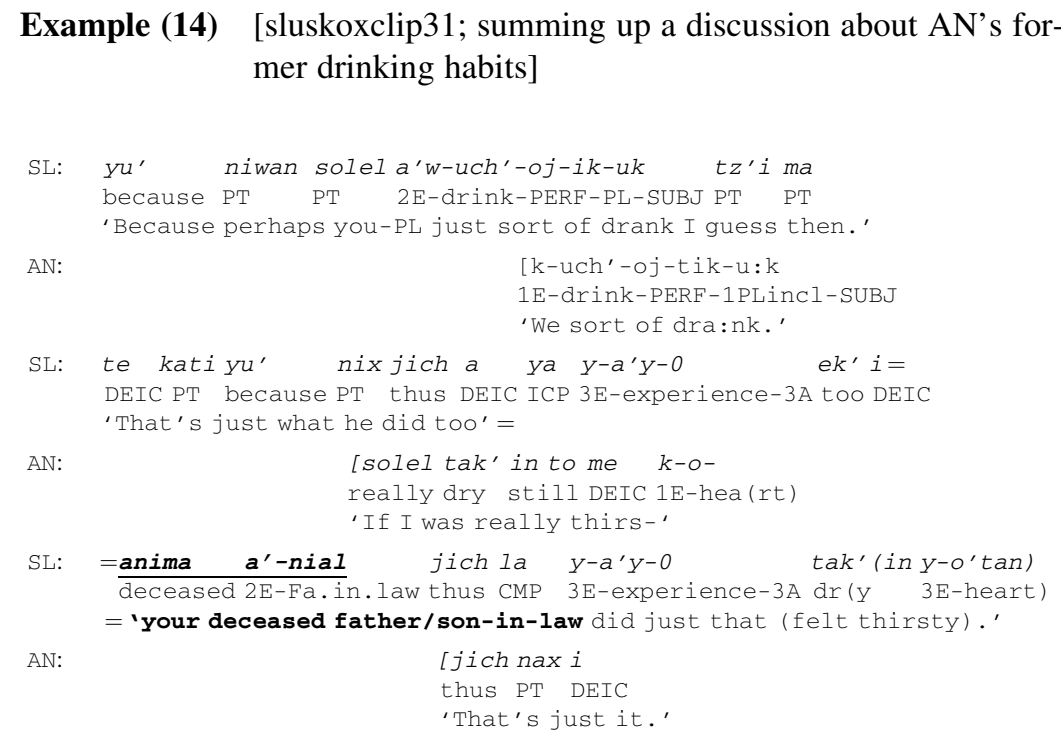

SL's husband, though AN's age mate when he was alive, is AN's classificatory 'father/son-in-law' because SL's Gomez surname makes her his wife's wix (elder sister). These cases in Examples (13) and (14) might suggest that the tendency to reckon through the addressee is not generic but exists when other constraints prevent reckoning through the speaker, here the constraint on mention of one's own spouse with a relationship term reckoned through oneself (see Levinson, this volume, on person-reference taboos).

However, Example (15) (like the one in Example (11)) is a case of triangulated reckoning through a relationship to the addressee that is not accounted for in terms of a taboo on mentioning one's own spouse, and is indicative of a more general practice of relating members of one's own family, where possible, to one's addressee rather than to oneself. (Haviland, this volume, describes the same practice of 'altercentricity' in Tzotzil.) 
Example (15) [aluxperez, v27; AN is visiting, AL has been talking about his life here long ago in contrast to nowadays]

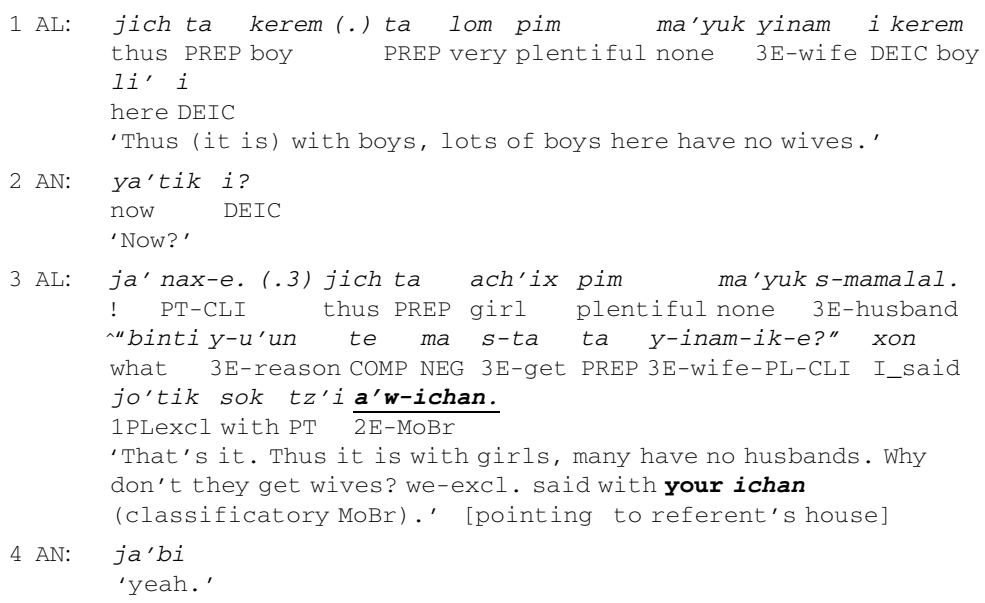

Here AL refers to his own adult son as a'wichan 'your mother's brother', a classificatory term that includes mother's brother's sons. His own son is AN's 'mother's brother's son' by virtue of the fact that his surname is Perez, which is also the surname of AN's mother, making him her 'brother'. The pointing gesture to this son's house nearby makes the reference unambiguous.

Both the need for explicitness to narrow down the field of possible referents, and cultural taboos like the one on mentioning one's own spouse motivate these sometimes extended but still minimal reference forms.

\subsubsection{Non-minimal initial person references}

Around 10 per cent of initial references to third persons in my data involve two or more referring expressions, more than one noun phrase, even when one could, in the context, be recognitional by itself. Is this evidence of the non-applicability of Schegloff's Preference Rule 2 (use a minimal form)? Or evidence of lack of uptake on the recipient's part? Or evidence that other things beyond simply referring are being done? In examining the excerpts below, I will try to distinguish cases where there is a sequential explanation (a micropause, or recipient looks blank, or doesn't react) from those requiring another explanation.

To understand the examples that follow, it is necessary to know a few things about the Tzeltal conversational feedback system. Repetition of all or part of the prior utterance is the normal (default) response to new information (Brown 1998). A mere 'Hm' by the recipient instead of a repeat is a minimal response that will, in this context, often be taken as not fully accepting or understanding 
the prior utterance. 'Hm' as a response to an initial person reference may be taken, analogously to a pause, as lack of prompt uptake, in contrast with ja' bi 'That's it', which provides firm uptake. Further, in this society mutual gaze is restricted and visual signals of feedback (nods, etc.) are minimal, so lack of mutual gaze cannot necessarily be taken as absence of uptake (Levinson and Brown 2004).

Some non-minimal person references are prompted by slow or hesitant uptake by the recipient. In Example (16), the initial reference 'sir over there at the viewpoint' is promptly expanded with a role label 'sir curer':

Example (16) [sopa; AN and AS are talking about old times]

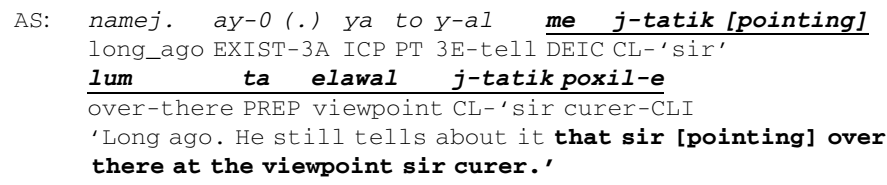

At ya to yal 'he still tells about it' AS gazes towards referent's home base and points to it, then turns her gaze to the recipient AN. At elawal 'viewpoint', AS and AN are mutually gazing but the recipient gives no nod or other response indicating comprehension of the referent. Here we may attribute expansion after 'viewpoint' as upgrading the information provided so far, without any discernable pause. Note that the upgrade is with a role description, not a name (though the curer's name is known to both participants).

In Example (17), two pieces of information, kin relation to speaker ('my deceased grandfather') and name ('Petul Ch'ijk) are supplied in the initial formulation, and after unenthusiastic uptake the speaker adds the referents' relation to someone the recipient definitely knows ('the father of the former elder-brother policeman Antun Ch'ijk):

Example (17) [aluxperez v28; asking about SCL]

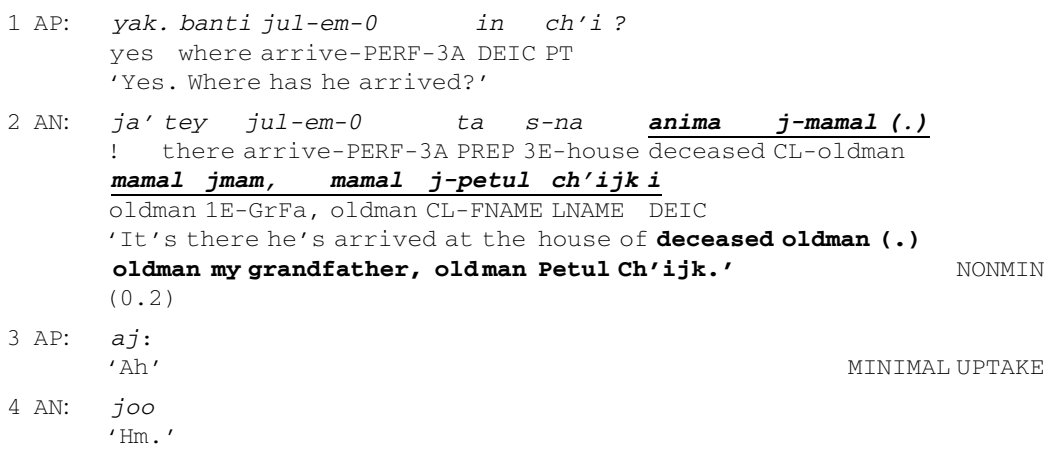




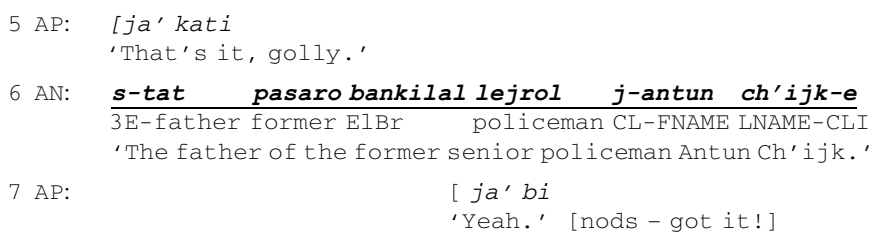

In line $1 \mathrm{AP}$ asks for a place identification, and $\mathrm{AN}$ responds in line 2 with a non-minimal form ('deceased' + kin term + name). After minimal uptake he expands it into another kinship + role + name reference that places the referent in relation to someone more widely known.

Slow or unenthusiastic uptake is not always an apparent motivation for expanded reference forms. In some cases, however, there is no clear sequential motivation for formulating the referent in two (or more) ways, as in Example (18) ('the two boys' plus 'my younger brothers'):

Example (18) [aluxperez p75, AN telling AP about his father's second wife's shortcomings, including being unkind to his (AN's) siblings, her stepsons]

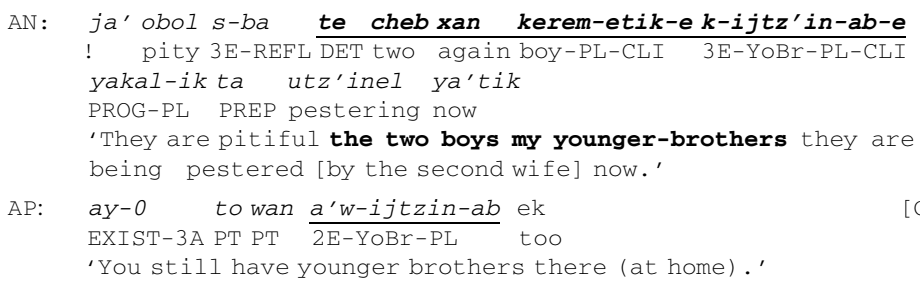

Either 'the two boys' or 'my two younger-brothers' would have sufficed to identify the referent in this context of talk about his father and stepmother at home.

Multiple reference forms in initial reference may be prompted by desire for explicitness, pinning the reference to a unique individual, as in Example (19) ('my deceased grandfather the father of my deceased mother'). Both paternal and maternal grandfathers are called mam.

Example (19) [nail, p18]

AO: hm, yu'n na'xlaj kapal a te anima j-mam-e

hm because PT QUOT like DEIC $\overline{\text { DET deceased CL-GrFa-CLI }}$ 


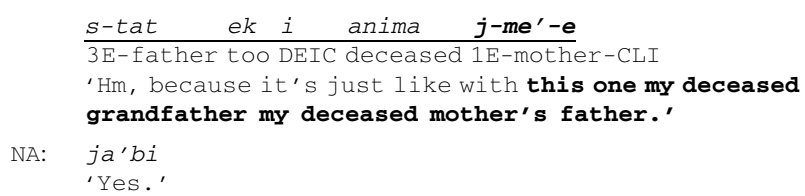

Reasons for non-minimal person reference forms other than lack of prompt uptake include particular cultural expectations. As we have seen, there is a preference for kinship reckoning to be done through the recipient rather than through oneself, although the most general preference is to reckon the referent through speaker or addressee if possible. If both are possible, then the tendency is to reckon through the addressee. In the non-minimal situations where something marked is being done, another motivation for non-minimal forms is an apparent preference for locating the referent in relation to both the speaker and the addressee, as in Example (20) (from the conversation cited in Example (12) about the son who didn't show up for a hearing because he was summoned to work).

Example (20) [manosil \& AO, v16A]

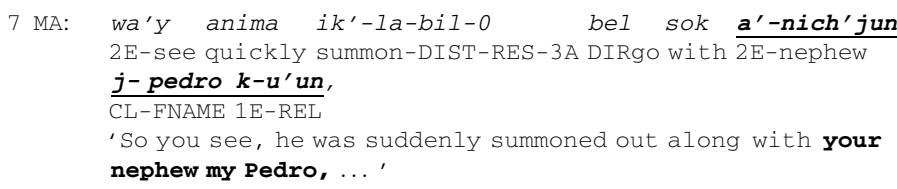

The list of people summoned to work includes a formulation of the speaker's own son as 'your nephew my Pedro', reflecting the preference for associating the referent to both speaker and addressee.

This tendency shows up frequently in conversational narratives, as in Example (21):

Example (21) [CLIP1sopa; talking about a great locust plague that happened long ago]

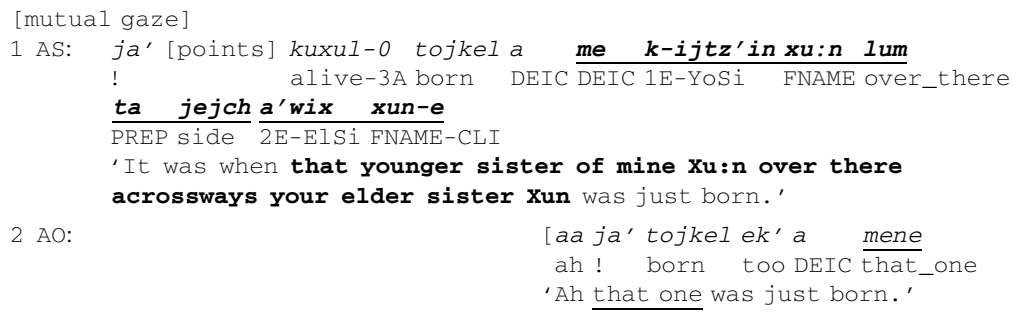




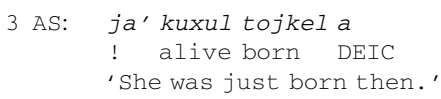

In this double formulation, 'your ElSi Xun' adds nothing to the informativeness of the reference beyond what was provided by 'that younger sister of mine Xun', since innumerable 'younger sisters' of AS will be 'older sisters' of her addressee AO.

A related tendency generating non-minimal reference forms in conversational narratives is a matter of relating the referent to both the time of the story (i.e., long ago) and the time of the telling (now), as in Example (22), where the narrator launches the story with non-minimal introduction of participants (lines 1 and 15), placing them in relation to current people known to the interlocutor.

Example (22) [clip3Sopa; talking about when the soldiers came through long ago] [AS gazes at AO after sme' tz'i men in line 1]

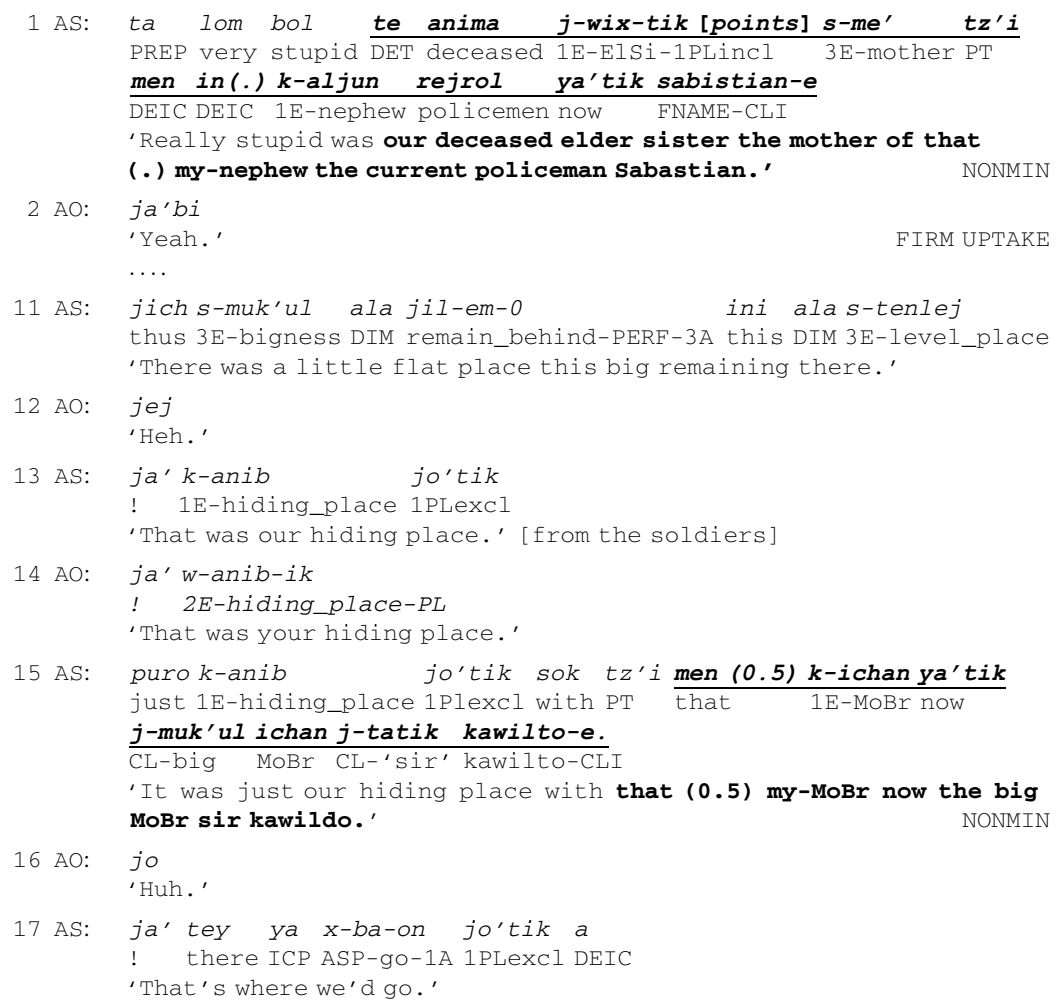


Some cases of initial person reference illustrate the cultural preoccupation with kin and geographic setting, with much time spent establishing a referent's place in the social network to make sure that reference is achieved, as in Example (23), where AN is telling AP about the time that AN's father came to this paraje looking for a wife:

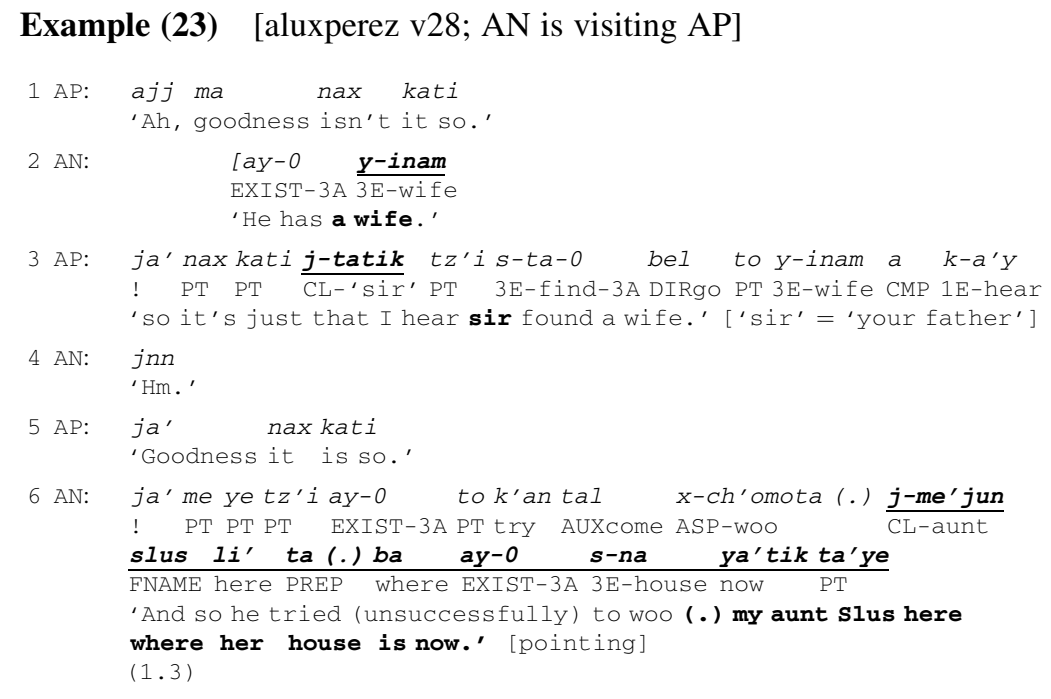

AN makes the initial reference to a woman his father tried to woo in line 6 by connecting her to himself ('my aunt Slus') and to where she now lives (pointing), and although the reference is taken up with an implicit acknowledgement in line 7, he expands the reference in line 8 to specify her father, AN's deceased grandfather Lorenzo:

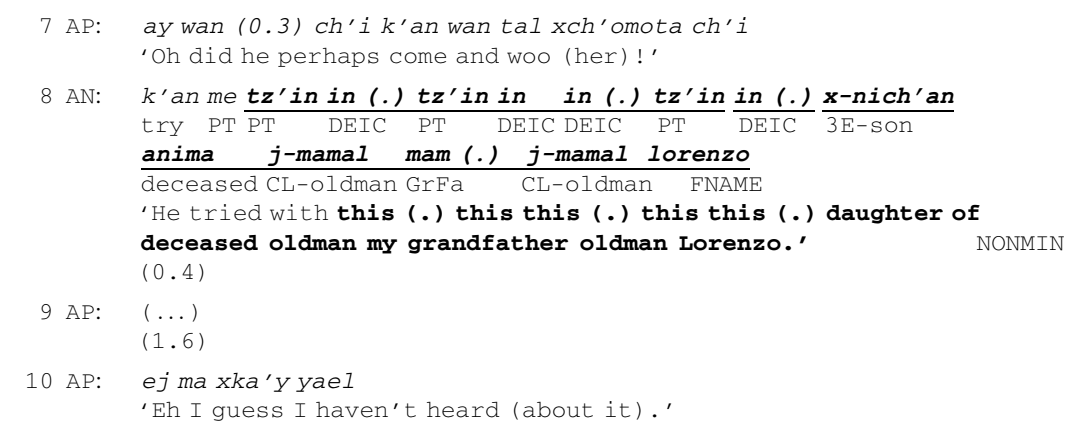

Failing to get recognition, AN expands further by connecting the referent to even more people, placing her as a namesake of his deceased mother, then 
placing her via name and kin relation and location (with a point) to Xpet Perez married to an Uch' man (whom AP is more likely to know); recognition is acknowledged (with oh that one!) in line 12:

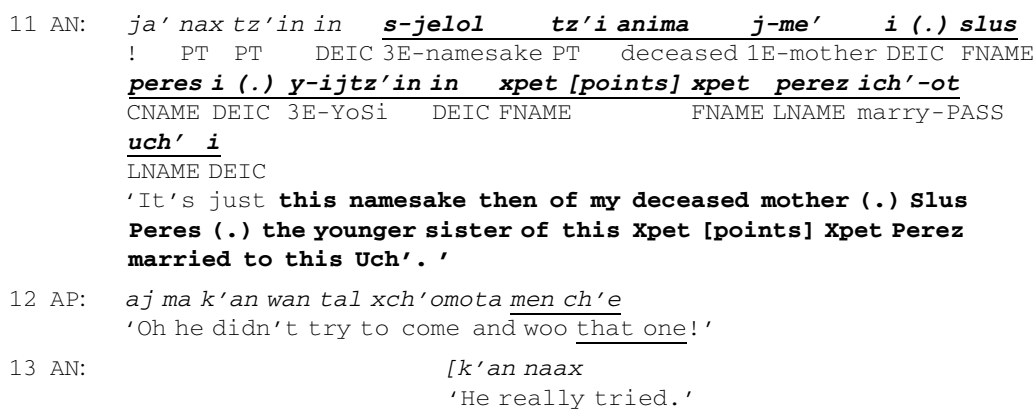

Tracking kin relations and person knowledge in this way has the function of updating common ground between people who are not up-to-date with one another's life. This is important in this society; one needs to know the relationship links between people, and a considerable amount of conversational time is spent updating this information.

\subsubsection{Repair}

Further insights into principles of person reference can be drawn from cases when reference apparently fails, when uptake is slow or inadequate. When a recipient fails to identify a referent, in what order does a speaker add additional specifications? Is this done incrementally, as the Sacks and Schegloff rules predict? Here are some examples. In Example (24), in response to a question about his land down in hot country, A replies in line 3: 'They have taken it away' (see Example 4). This is not enough; in line 4, PK asks 'who?' AN replies with a kin description: 'the son of deceased oldman my uncle' and then adds (after a half-second pause) 'the husband of Mrs. Xilom As,' likely figuring that the recipient might not know the son (no name given), but will know the mother.

Example (24) [mampak2; talking about AN's cornfields]

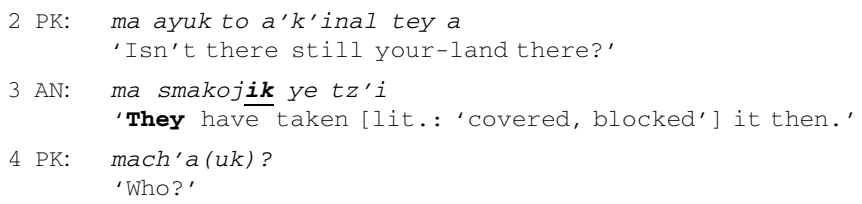




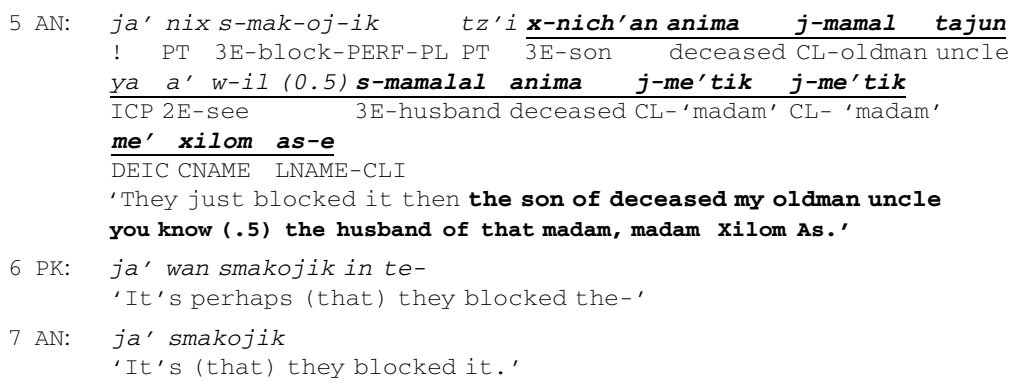

Failure of minimal reference may result in non-minimal elaboration as an upgrade, as in Example (25):

Example (25) [mampak; still talking about AN's land]

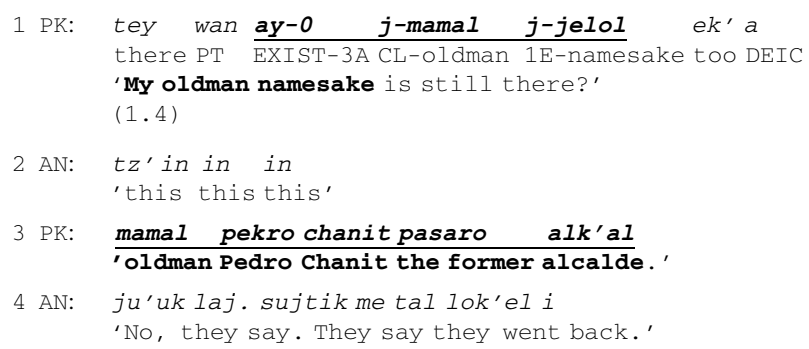

Example (25) illustrates another tendency - when recognition is not achieved, upgrading is often done with non-minimal, multiply specified, reference forms. This is another deviation from Sacks and Schegloff principles, with upgrades not necessarily incremental but elaborated all at once, in one breath.

These examples reveal that there are not always particular sequentiallybased motivations for using non-minimal referring expressions, reasons to do with identification of referent (lack of uptake, common ground worries), that can account for these expanded forms.

\subsection{Summary: Tzeltal person-reference practices}

We have seen that, in recognitional references to members of the community, some or all of the following are routinely used in Tzeltal:

$$
\begin{aligned}
& \text { 'deceased' }+ \text { honorific }+ \text { 'oldman'/'woman' }+ \text { kin term }+ \text { title }+ \\
& \text { name }+ \text { location }+ \text { point }
\end{aligned}
$$

All of this is often, in the context, default information, non-remarkable. The order of mention is important: Like in the game of twenty questions, the 
formulation narrows down the range of possibilities, starting relatively general and going more specific if necessary. The sequence seems to be designed to be truncated if possible, at the first strong sign of recognition by the recipient.

The examples I have presented show that simple treatment-of-a-referent-aswithin-recipient's-common-ground is often taken to be not enough in Tzeltal person reference. Formulations of person reference frequently convey things beyond referring simpliciter, things like respect to referent, respect to recipient, orientation to the presence of overhearers, taboo avoidances, and other culturally important observances (see Enfield, this volume). Non-minimal recognitional references signal that something else is being done besides simply trying to achieve recognition in the most efficient manner. What else is being done includes marking the referent's social identity, pre-empting possible misidentification of the referent, indexing the relationship between speaker and addressee, updating the social person-log in the participants' common ground, all things that are routine, unremarkable in the context. In this they are distinct from deviations from the expected, routine formulation to express an attitude to the referent or a stance towards the topic.

\subsection{Principles of person reference instantiated in Tzeltal}

What then are we to make of the non-minimal person references that crop up in Tzeltal conversation? There are three possible interpretations of the facts that I have presented. The first is to claim that the preference for minimization is culture-specific, and does not apply to Tzeltal person reference. This is belied by the numbers - 90 per cent of the person references in my data set are minimal - suggesting that Tzeltal speakers do indeed have a preference for minimization. Minimality is also supported by cases of interactionally generated expansions that are attuned to the level of uptake.

The logical second interpretation is that the principle of minimization is universal. However, this is belied by cases where non-minimal expressions are unremarkable in the local contexts examined above. A third interpretation is the one that seems to be supported by the Tzeltal data: The preference for minimization is universal but is affected differently by other preferences in the system operating in particular cultural contexts. I would like to suggest that there is a third principle, relatively invisible in English but unmarked in Tzeltal, a principle favouring 'association':

Principle 3: Associate the referent as closely as possible to the current conversation participants.

In Tzeltal this is realized in the practice of reckoning the referent through either or both speaker and addressee, or through another relationship connected to speaker or addressee. It seems that, if recognition can be achieved using a 
single referring expression that associates to speaker or to addressee, then minimization is also generally observed. If not, minimization yields to association. Doing this (saying things like 'our-inclusive elder sister', 'your eldersister's son my Pedro', etc.) is unremarkable in the context, not conveying anything special beyond person reference.

Note that, in calling this third principle a 'preference', I do not mean that if you do not follow Principle 3, Tzeltal people are surprised, or think that you are doing something special. It's one extremely common practice, courteous and routine, but it is not obligatory. This third principle is perhaps a natural outcome of using possessed kin terms as a default; it also appears to be operative in two other Mayan cultures - Tzotzil (Haviland, this volume) and Yucatec (Hanks, this volume) - and it is a common solution in taboo situations in Yéli Dnye (New Guinea, Levinson, this volume). We might expect it to turn up in other societies where kinship terms are the default for person reference.

Preference 3 is apparent in the Tzeltal data. But Stivers, Enfield and Levinson argue (introduction, this volume) that it is not just a Tzeltal idiosyncrasy, it is observably operative in English conversation as well, most noticeably in nonrecognitional reference, and that different orderings of the preferences account for the priority Tzeltal gives to Preference 3 over Preference 2, in contrast to the preferences in English person reference.

Orientation to these three principles gives Tzeltal person reference a universal interpretability. The characteristic local flavour of Tzeltal person reference derives from a combination of at least four things:

(1) the different weighting given to Preference 3, in comparison with English usage. Principle 3 - association - trumps minimization in Tzeltal at least some of the time, but not in English where it is restricted to non-recognitionals;

(2) 'altercentricity' - reckoning through addressee rather than speaker;

(3) the kinship and naming systems, which mean that name alone or kin-term alone often are insufficient for recognition;

(4) particular taboos, like that against naming or using a kin term for one's own spouse.

What then does Tzeltal tells us about person reference in general? Like in English, we find alternative forms carry additional social information (Stivers, this volume). Like in Lao, we find expanded referring expressions that are minimal, carrying obligatory social information (Enfield, this volume). Like in Yéli Dnye, we find taboos constraining the use of names (Levinson, this volume). Like in many societies around the world, kinship takes precedence over names when referring to persons. And kinship as the default seems to raise the importance of a preference for association. 
There are implications of having kinship as the default person-reference form rather than names, since kinship terms apply to larger collectivities of individuals than do names. Relying on kinship means that initial person references are likely to be more elaborated than in speech communities where names are the default.

Updating this person information is an important activity in and for itself. Tenejapans care about kin relations, the most important social information about anyone in their society. They spend a lot of conversational work establishing them in the discourse and reminding each other about them. They also dwell on where people live, used to live, and when things happened in relation to where people live(d). The form of initial person reference sometimes introduces news - for example, anima - goodness, has she died? providing scope for topic elaboration about just what happened to her.

The person-reference forms we have examined in Tzeltal are generally compatible with the conversational principles that have been established for initial person reference in other languages. We can conclude that interaction does indeed seem to have universal structures, yet in the domain of person reference it has local colouring due to culture-specific constraints. Persons are socially loaded referents, and societies circumscribe what you can say about them in particular ways.

\section{Abbreviations}

1/2/3E First/Second/Third Person Ergative (marking 'ergative', possessor)

1/2/3A First/Second/Third Person Absolutive

ACS Achieved change of state particle

ASP Neutral aspect

ATP Antipassive

AUX Auxiliary

BEN Benefactive derivation

CAUS Causative derivation

CL Classifier

CLI Clause-final clitic

CMP Completive

CNAME Clan name

COMP Complementizer

DEIC Deictic particle

DET Definite determiner

DIM Diminutive

DIR Directional

DIST Distributive 


$\begin{array}{ll}\text { EXIST } & \text { Existential predicate } \\ \text { FNAME } & \text { First (given) name } \\ \text { ICP } & \text { Incompletive } \\ \text { LNAME } & \text { Last (lineage) name } \\ \text { MCNAME } & \text { Mother's clan name } \\ \text { NEG } & \text { Negative } \\ \text { PASS } & \text { Passive } \\ \text { PERF } & \text { Perfect derivation } \\ \text { PL } & \text { Plural } \\ \text { PLNAME } & \text { Place name } \\ \text { PREP } & \text { Generic preposition } \\ \text { PT } & \text { Particle } \\ \text { PROG } & \text { Progressive } \\ \text { Q } & \text { Question particle } \\ \text { QUOT } & \text { Quotative } \\ \text { RED } & \text { Reduplication } \\ \text { REFL } & \text { Reflexive pronoun } \\ \text { REL } & \text { Relational noun } \\ \text { RES } & \text { Resultative derivation } \\ \text { SG } & \text { Singular } \\ \text { SUBJ } & \text { Subjunctive } \\ ! & \text { Predicator ('it is the case that') }\end{array}$

